заинтересованных сторон, вовлеченность компании в жизнь сообщества и заинтересованность в повышении качества жизни.

Внедрение стандартов ISO 26000 рассматривается как первый этап оценки состояния управления компанией по отношению к этому стандарту. Главная задача такой оценки - выявить области развития, повысить эффективность управления в сфере социальной ответственности организации. Эта задача приобрела особую актуальность в современных условиях экономической неопределенности.

Заключение.

Подводя итог, стоит еще раз отметить, что разработка единого стандарта социальной отчетности - на сегодняшний момент одна из важнейших проблем, стоящих на развития экономической и социальной сферы и вовлечения общества в устойчивое развитие данных сфер.

На основании изученного мною материала, можно сделать вывод о том, что реализация концепции корпоративной социальной ответственности в соответствии с ожиданиями и предпочтениями заинтересованных сторон будет не только способствовать развитию общества, но в долгосрочной перспективе, повысить экономическую эффективность компании. Поэтому всем хозяйствующим субъектам, а также общественно-экономическим организациям, не стоит пренебрегать актуальностью развития и внедрения системы оценки социальной ответственности бизнеса и разработкой единого стандарта отчетности.

$$
* * *
$$

1. Воробьева О.А. Исторический экскурс: концепция корпоративной социальной ответственности как теоретическая основа нефинансовой отчетности // Российское предпринимательство. — 2015. - Том 16. 一 № 8. - c. 1111-1120.

2. Жойдик А.П. Методы оценки корпоративной социальной ответственности бизнеса // Российское предпринимательство. - 2013. — № 6 (228). - с. 94-98.

3. Николаев Н. А. Корпоративная социальная отчетность: проблемы повсеместного внедрения. // Федеральное государственное автономное образовательное учреждение высшего образования "СПбПУ Петра Великого". - 2013. - с. 501-505.

4. Официальный сайт Глобальной инициативы по отчетности - [Электронный ресурс]. - 2017 - Режим доступа:- https://www.globalreporting.org/Pages/default.aspx (дата обращения: 15.03.2017).

5. Стандарт ГОСТ ИСО 26000 - [Электронный ресурс]. - Режим доступа : - http://spbtpp.ru/wpcontent/uploads/2015/11/law_national_standart.pdf

6. Торгово-промушленная палата РФ. Официальный сайт. - [Электронный ресурс]. - Режим доступа: http://tpprf.ru/ru/news/-i3813/ (дата обращения: 14.03.2017).

\title{
Исмагилов А.Н. \\ Некоторые аспекты социально-экономического расслоения вроссийском обществе в постсоветский период
}

Финансовый университет при Правительстве РФ (Россия, Москва)

doi: $10.18411 / l j-30-04-2017-1-10$

idsp: 000001:lj-30-04-2017-1-10

\section{Аннотация}

В настоящей статье рассмотрена проблема социального неравенства современного российского общества. Определены истоки постсоветского неравенства, а также проведен анализ некоторых аспектов: заработная плата, уровень доходов различных групп населения, ЖКХ. Выявлены тенденции социального неравенства современной России.

Ключевые слова: социальное неравенство, реальные доходы населения, зарплата, дифференциация регионов, тенденции расслоения общества

1. Социально-экономическое неравенство в российской истории: к постановке вопроса. Проблема социально-экономического неравенства всегда была актуальна для российского народа. Многочисленные факты социальной и имущественной дифференциации общества легко прослеживаются с самых ранних этапов становления Древнерусского государства вплоть до современности; их значительное влияние на ход 
развития страны подтверждается историко-ретроспективным анализом. Однако представляется, что наиболее острое звучание данный вопрос приобрел в новейший период нашей истории: после распада СССР в 1991г.

Резкая смена политического режима и переход к рыночной экономике кардинальным образом изменили жизнь многих социальных групп, что повлекло за собой серьезные сдвиги в их материальном и социальном положении. Цель настоящей работы на основе анализа ряда базовых социально-экономических статистических показателей ответить на следующие вопросы: каков уровень и динамика социально-экономического неравенства в постсоветской России? Каковы тенденции формирования среднего класса в российском обществе? В каких сферах экономики РФ самые низкие доходы? Есть ли различия в доходах по регионам? Как соотносятся российские показатели с общемировыми?

2.Истоки постсоветского неравенства. Одним из факторов, который предопределил интенсивность и масштабы будущего расслоения социума, стали традиционно невысокие жизненные стандарты, заданные социалистическим обществом: в Советском Союзе минимальные доходы ориентировались на физиологический уровень прожиточного минимума. Однако развитие капиталистических, рыночных отношений способствовало тому, что экономически активные группы стали ориентироваться на потребительские принципы западного общества. Это усилило разрыв между минимальными доходами и демонстративным потреблением «новых богатых» [1]. Миллионы людей в 1990-е годы оказались на грани нищеты. Это подтверждает официальная статистика: в 1992г. численность населения с денежными доходами ниже величины прожиточного минимума составляла 33,5\% (примерно 50 млн. человек) [2]. Величина этой категории населения на протяжении 1990-х гг. не опускалась ниже $20 \%$, а после кризиса 1998г. вновь достигла почти 30\%. Безусловно, за более чем 20 лет уровень жизни населения вырос, однако и сегодня он оставляет желать лучшего: в последние несколько лет около 10\% населения России имеет доходы ниже прожиточного минимума, и на октябрь 2016 г.это число колеблется около 19 млн.человек.

3. Статистические показатели уровня социально-экономического неравенства и их анализ. Один из статистических показателей, отражающий уровень социального расслоения в обществе - индекс Джини. Величина данного показателя может варьироваться от 0 до 1. Чем выше его значение, тем более неравномерно распределены доходы в обществе[3]. В следующей таблице представлены статистические показатели коэффициента Джини исследуемого периода [2]:

\begin{tabular}{|c|c|c|c|c|c|c|c|c|c|c|c|c|}
\hline Год & 1997 & 1998 & 2000 & 2001 & 2003 & 2005 & 2007 & 2008 & 2009 & 2010 & 2011 & 2012 \\
\hline Инд. & 0,390 & 0,394 & 0,395 & 0,397 & 0,403 & 0,409 & 0,422 & 0,421 & 0,421 & 0,421 & 0,417 & 0,420 \\
\hline
\end{tabular}

Для наглядности и полноты понимания рассмотрим значение этого показателя в других странах мира и сравним их с Россией [4]:

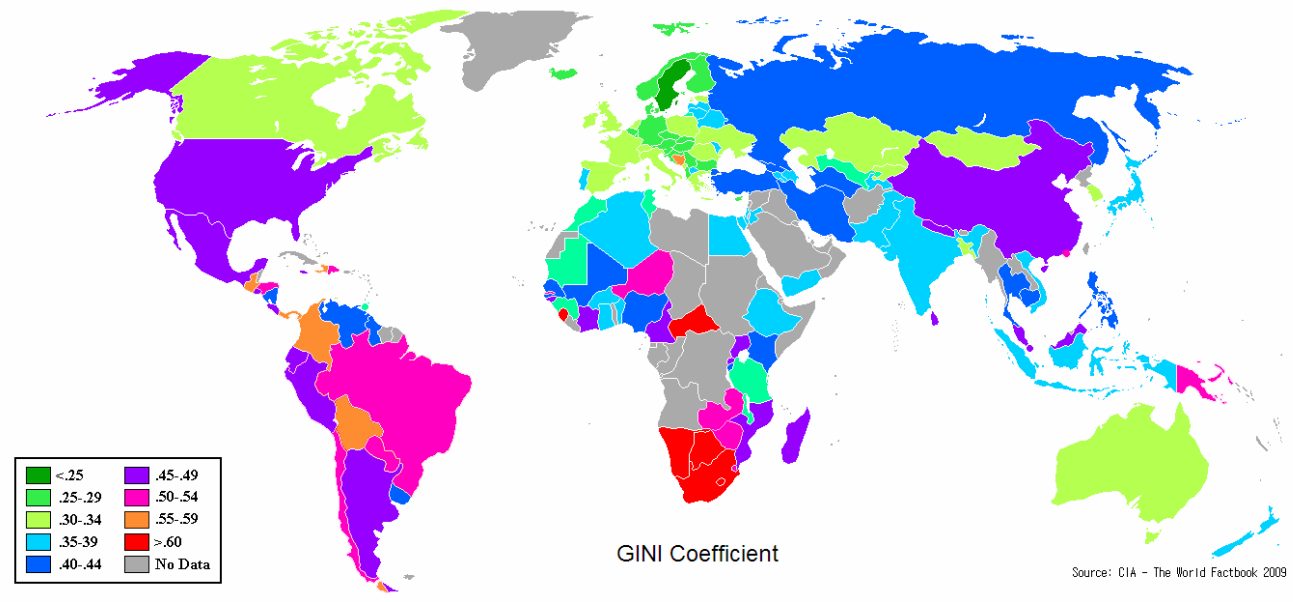

Данная карта демонстрирует, что, согласно коэффициенту Джини, социальноэкономическое расслоение в России имеет среднее значение для мирового сообщества, являясь не слишком высоким, но в то же время и не минимальным. Примерно такая же 
ситуация сложилась в Венесуэле, Уругвае, Турции, Иране, Туркмении; отметим, что социально-экономическое расслоение в таких странах как США и Китай даже несколько выше, чем в Российской Федерации.

Теперь воспользуемся еще одним инструментом, отражающим уровень социального и имущественного расслоения в обществе - децильным коэффициентом, который демонстрирует соотношение между первой $10 \%$-й(беднейшей) и последней $10 \%$ й (богатейшей) группами населения [3]. В ниже приведенной таблице продемонстрировано значение этого показателя для Российской Федерации в период с 1995 по 2012 гг. [2]:

\begin{tabular}{|c||c|c|c||c|c|c||c||c|c|c|c||c||c||c||}
\hline \hline Год & 1995 & 1997 & 1998 & 1999 & 2000 & 2002 & 2004 & 2006 & 2007 & 2008 & 2009 & 2010 & 2011 & 2012 \\
\hline \hline $\begin{array}{c}\text { Дец. } \\
\text { коэф. }\end{array}$ & 13,5 & 13,6 & 13,8 & 14,1 & 13,9 & 14,0 & 15,2 & 15,9 & 16,7 & 16,6 & 16,6 & 16,6 & 16,2 & 16,4 \\
\hline \hline
\end{tabular}

Исследователи полагают, что значение децильного коэффициента больше десяти означает высокую степень социально-экономического неравенства в обществе. Такое расслоение опасно для страны тем, что в ней имеется и увеличивается гипотетическая вероятность возникновения беспорядков, протестов, столкновений различных социальных групп, появляется и возможность государственного переворота. Объясняется это тем, что столь значительная разница между бедными и богатыми слоями население есть очевидное свидетельство несправедливости социально-экономической организации данного общества. Из приведенных статданных видно, что в современной истории России значение этого показателя еще не опускалось ниже 10, что говорит о высокой степени расслоения российского общества. Децильный коэффициент со всей очевидностью демонстрирует, насколько велика пропасть между самыми богатыми и самыми бедными слоями российского населения, насколько сильно отличается их материальный уровень жизни. В последние годы - 2014-2016 гг. прослеживается тенденция дальнейшего ухудшения благосостояния основной массы народа. Это касается и уровня заработной платы, и общих доходов населения в целом.

4. Заработная плата, реальные доходы и средний класс. Остановимся на статистике за 2014-2015 гг. подробнее. На графике представлена динамика реальной заработной платы и реальных доходов населения [5]:

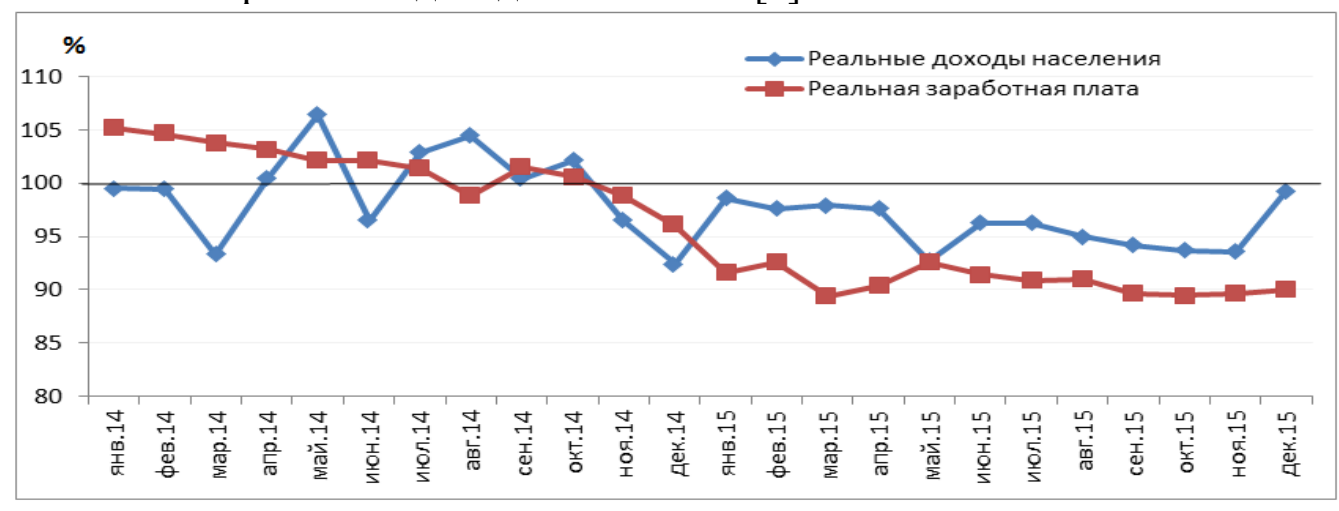

Одним из главных факторов снижения доходов населения стала инфляция, которая по итогам года составила $12,9 \%$, а ежемесячно колебалась от менее чем 0,5 до почти $4 \%$ [2]. Банкротство многих фирм и сокращение рабочего персонала существенно ухудшили ситуацию на рынке труда. В результате, на протяжении почти всего 2015 года безработица росла;на конец2015 года общая численность безработных в стране составила 4 млн. 426 тыс. человек, что на 375 тыс. человек выше показателя предыдущего года[2]. По данным исследований, проведенных в РАНХиГС, доля среднего класса в России упала к концу 2015 г. с 20 до 15\%. Как известно, стабильность общества во многом зависит от крепкого, многочисленного среднего класса. По данным банка CreditSuisseк среднему классу можно отнести всего лишь 4,1\% населения нашей страны [6]. В западных странах к среднему классу относится 40-70\% населения. Стоит отметить, что эта тенденция стала результатом сокращения доходов, а не результатом перераспределения общественного богатства: одновременно с уменьшением среднего класса происходит увеличение бедных 
людей. Ниже приведена таблица, демонстрирующая численность среднего класса в различных странах мира [5]:

Численность среднего класса в странах мира, по расчётам

Credit Suisse

\begin{tabular}{|l|c|}
\hline Страна & Доля среднего класса, \% \\
\hline Австралия & 66,1 \\
\hline Италия & 59,7 \\
\hline Великобритания & 57,4 \\
\hline Испания & 55,8 \\
\hline Новая Зеландия & 50,3 \\
\hline Греция & 47,2 \\
\hline Южная Корея & 44,6 \\
\hline Германия & 42,4 \\
\hline США & 37,7 \\
\hline Китай & 10,7 \\
\hline Бразилия & 8,1 \\
\hline Россия & 4,1 \\
\hline Индия & 3 \\
\hline
\end{tabular}

5. Самые низкие доходы: аграрная сфера. Рассмотрим конкретные группы населения. Хотя важнейшей отраслью экономики страны остается сельское хозяйство, занятые именно в этой отрасли получают самые низкие зарплаты [2]. Даже несмотря на проведение политики импортозамещения, привлечение людей заниматься производством сельскохозяйственной продукции, с июля 2015 года количество людей, прекративших фермерскую деятельность, стало больше тех, кто стал фермером, что отражено в следующих статистических данных налоговой службы [7]:

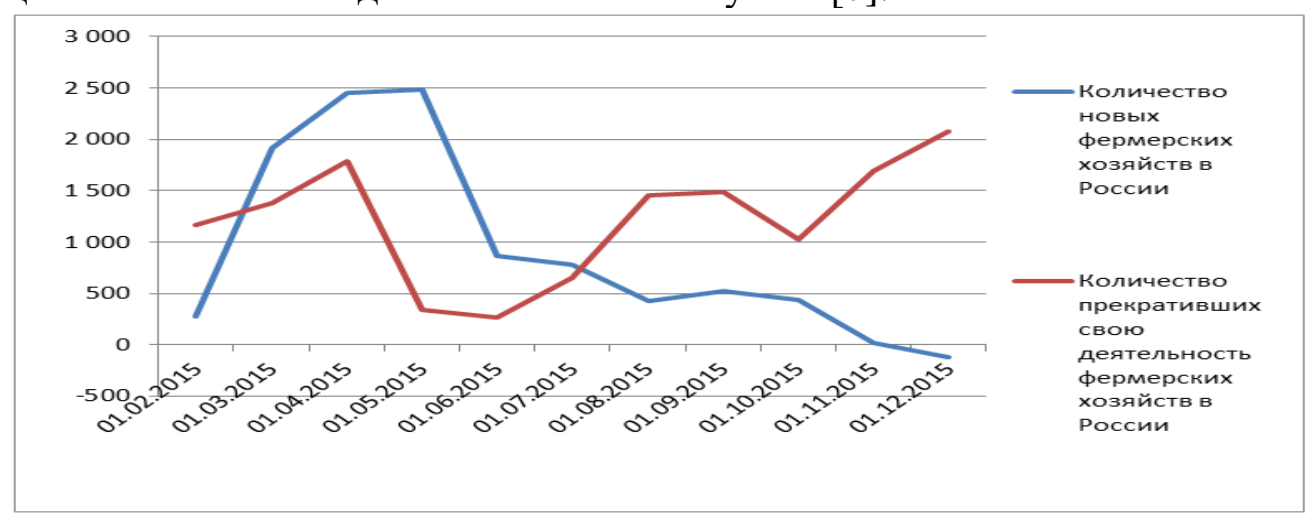

6. ЖКХ: дифференциация регионов. Нельзя обойти стороной и болезненную тему для многих россиян - ЖКХ. Сравнение коммунальных платежей по регионам показывает огромную разницу между ними [5]:

\begin{tabular}{|c|c|c|c|c|c|}
\hline Город & $\begin{array}{c}\text { Мин. } \\
\text { тариф за } \\
\text { капремон } \\
\text { т, } \\
\text { руб./кв.м. }\end{array}$ & $\begin{array}{c}\text { Средняя } \\
\text { плата за } \\
\text { капремонт за } \\
\text { однокомнатн } \\
\text { ую квартиру } \\
(33,8 \text { кв.м })\end{array}$ & $\begin{array}{c}\text { Коммунальн } \\
\text { ые платежи* } \\
\text { из расчета на } \\
1 \text { чел. в } \\
\text { квартире по } \\
\text { региональны } \\
\text { м } \\
\text { нормативам }\end{array}$ & $\begin{array}{c}\text { Сумма } \\
\text { коммунальн } \\
\text { ых платежей } \\
\text { и платы за } \\
\text { капремонт }\end{array}$ & $\begin{array}{c}\text { Платеж по } \\
\text { нормативам } \\
\text { от } \\
\text { среднемесячн } \\
\text { ой } \\
\text { номинальной } \\
\text { заработной } \\
\text { платы с } \\
\text { вычетом } \\
\text { НДФЛ, в \% }\end{array}$ \\
\hline Москва & 15 & 507 & 1963,92 & 2470,92 & 4,61 \\
\hline Воронеж & 6,6 & 223,08 & 4224,84 & 4447,92 & 18,37 \\
\hline $\begin{array}{l}\text { Санкт- } \\
\text { Петербург }\end{array}$ & 2,5 & 84,5 & 2235,51 & 2320,01 & 6,17 \\
\hline Севастополь & 6,16 & 208,2 & 1715,84 & 1924,04 & 8,71 \\
\hline Екатеринбург & 8,2 & 277,16 & 2954,34 & 3231,5 & 12,15 \\
\hline Пермь & 7 & 236,6 & 3970,66 & 4207,26 & 17,56 \\
\hline Владивосток & 6,57 & 222,06 & 4143,82 & 4365,88 & 15,02 \\
\hline Махачкала & 5,2 & 175,76 & 998,17 & 1173,93 & 7,32 \\
\hline
\end{tabular}


Мы видим довольно значительную разницу даже между двумя столицами, не говоря уже об остальных городах - представителях различных федеральных округов, что в какой-то мере говорит о неравенстве граждан одной страны, но разных субъектов РФ.

7. Дифференциация доходов прослеживается даже среди представителей одной профессии. Это также зависит отопределенного региона нашей страны. Например, рассмотрим среднюю заработную плату преподавателей образовательных учреждений высшего профессионального образования за январь-март 2016 г. [2]:

\begin{tabular}{|c|c|}
\hline & Средняя заработная плата, рублей \\
\hline Российская Федерация & 44612 \\
\hline Центральный федеральный округ & 55647 \\
\hline г.Москва & 72016 \\
\hline Северо-Западный федеральный округ & 46395 \\
\hline г.Санкт-Петербург & 48366 \\
\hline Южный федеральный округ & 34463 \\
\hline Северо-Кавказский федеральный округ & 28403 \\
\hline Приволжский федеральный округ & 35919 \\
\hline Уральский федеральный округ & 45396 \\
\hline Сибирский федеральный округ & 40727 \\
\hline Дальневосточный федеральный округ & 50815 \\
\hline Крымский федеральный округ & 37129 \\
\hline
\end{tabular}

Видно серьезное различие зарплат даже внутри одного федерального округа: например, зарплата преподавателя в Москве больше почти на 20 тыс. заработной платы его коллеги в Центральном округе, к которому и относится Москва [2].

8. Заключение. Итак, проведенный анализ статистических данных позволяет сделать следующие выводы: во-первых, социальное расслоение, уменьшавшееся в началеХХІв., вновь приобретает тенденцию к увеличению из-за кризисных явлений в российской экономике, сокращений доходов и благосостояния населения страны. Вовторых, расслоение приобретает все большие масштабы, так как состоятельные люди, находящиеся в меньшинстве, богатеют и увеличивают свое состояние, а средний класс, наоборот, беднеет и превращается в бедняков. Правительству важно решить эту чрезвычайно острую проблему, создать все условия для обеспечения высокого уровня жизни, сократить разрыв между самыми бедными и самыми богатыми. На мой взгляд, без вмешательства государства (возможно, посредством изменения налогового законодательства или перераспределения бюджета) российскому обществу не удастся самостоятельно решить эту проблему и даже остановить тенденцию к усилению дифференциации населения.

$$
* * *
$$

1. Зубова, Л.Г. Социальное расслоение в России / Л.Г. Зубова //Мир России. Социология. Этнология. 2004. - №1. - C. 27-30.

2. Официальный сайт Федеральной службы государственной статистики [Электронный ресурс].-URL: http://www.gks.ru/ (дата обращения 14.10.2016)

3. Микроэкономика: практический подход (ManagerialEconomics): учебник / коллектив авторов; под ред. А.Г. Грязновой и А.Ю. Юданова. - 7-е изд., перераб. - М.: КНОРУС, 2014. - 688 с.

4. Официальный сайт ЦРУ [Электронный ресурс]. - URL: https://www.cia.gov/ (дата обращения 15.10.2016)

5. Центр Сулакшина (Центр научной политической мысли и идеологии) [Электронный ресурс]. - URL: http://rusrand.ru/ (дата обращения 16.10.2016)

6. Официальный сайт Credit Suisse [Электронный ресурc]. - URL: https://www.credit-suisse.com/ (дата обращения 16.10.2016)

7. Официальный сайт Федеральной налоговой службы [Электронный ресурс]. - URL: https://www.nalog.ru/ (дата обращения 15.10.2016) 